\title{
Psychological Peculiarities of Future Doctors Neurotization under the Trilingualism Condition
}

\author{
Olena Kostiuk, Yaroslav Tsekhmister, Vitalii Lunov
}

\begin{abstract}
The three-factor structure of the phenomenon of neurotization has been proposed. The content of the first factor, "Deficiency neurotization" is represented by the following personal traits of the trilingual students: in fact, the deficiency of the I-functions, disadaptability, conformality, nostalgia, alienation, unfavorable family situations, social tension, somatization, obsession, vegetative disorders. The content of the second factor, "Destructive neurotization", combines such phenomena as: the actual destructiveness of the I-functions, the experiences of the great influence of the parents' family, neuroticism, high social activity, somatic disorders, depression, hysterical type of response, high interference of concepts. The content of the third factor, "Anxious-ambivalent disadaptation" includes indexes of interactivity, depression, weakness of the I-function, hostility, phobia, paranoyality, anxiety, neurotic depression, asthenia, receptive language competencies.

It has been established that the factors influencing the course of disadaptation processes are factors of internal relation with the homeland, which manifest themselves in the sense of nostalgia and alienation. Somatization of manifestations of anxiety through the system of vegetative, depressive disorders, with low indexes of adaptability and high indexes of conformism, becomes one of the determinants of increasing neurotic conflict.
\end{abstract}

Keywords: trilingualism, deficiency of the I-functions, disadaptability, conformality, nostalgia, alienation, unfavorable family situations, social tension, somatization, obsession, vegetative disorders.

\section{INTRODUCTION}

Integration of Ukrainian education into the system of academic exchanges and academic mobility is an important factor in the establishment of dynamic international and intercultural relations and the development of the state. Ukraine has significant experience in providing educational services to foreign students, whose number has increased in recent years. Compared to 2000, the number of entrants invited to study in Ukraine has increased by 53\% and as of 2017 it amounts to more than 36 thousand persons from 129 countries of the world.

Foreign students as a separate socio-demographic group was the subject of scientific analysis in a number of cultural and sociological studies in the context of ethno-national, migration and demographic transformations, sociocultural factors of socialization of personality (O. Hurenko, F.Vlasenko, M.Vitkovska, T.Glebova , Y. Dorozhkin,

Revised Manuscript Received on November 15, 2019

* Correspondence Author

Olena Kostiuk , Assistant at Microbiology Department, Bogomolets National Medical University, Kyiv, Ukraine

Yaroslav Tsekhmister, Ed.D., PhD., Professor, Corresponding Member of National academy of educational sciences of Ukraine, Kyiv, Ukraine

Vitalii Lunov *, PhD, Associate Professor, Bogomolets National Medical University, Kyiv, Ukraine, email: lunyov_vitaliy@ukr.net
S.Lischenko, S. Rodonova, M. Faisal, R. Hayrullin, D.Yadransky); pedagogical and philological studies in the context of determining the factors of adaptation to the conditions of studying at universities (N. Bulgakov, N.Vasilenko, T.Dementieva, $\quad$ Y.Kmit, V.Kolomiets,N.Lavrichenko, V.Nikolaenko, O.Palka, N.Pomortseva, L. Rybachenko, V. Tarasenko, O.Tetyatchenko, N. Ushakova).

In general, psychological issues focused on the psychological support of the pedagogical process in the multidisciplinary institutions of higher education (I.Sladkikh, M. Ivanov, L.Ivankina), and only in a small number of researches - on the educational process in medical schools (G. Shapoval). Medico-psychological (in fact, genetic-psychological) problems, despite its unconditional significance, was not a subject of specific monographic or dissertation researches. In a number of studies (I.D.Beh, O.A.Gulbs, V.V.Klimenko, N.Yu.Maliy, O.A.Mamichev) it is determined that the content of the educational process and the organizational structure of higher educational establishments involves the creation of conditions with strict enough standards of behavior and a certain disregarding of specific students' personality features, which become the basis of conflicts (intrapersonal, intrapsychic, interpersonal) accompanied by a certain temporary neurotization and psychosomatization of the individual.

Highly important issue, as in view of its theoretical significance and practical value, is the determination of the conditions for the transformation of the usual conflict (in personality, in the educational space, the conflict of cultures) into a neurotic, since the specificity of the neurotic conflict, in comparison with the psychological, is not sufficiently differentiated at the level of the individual typologies and in accordance with the categories of activity mediation of personality development, which is the conflict situation of interaction in the educational space.

In the case of foreign students, the medical field, the corresponding processes are also complicated by communication at the level of interaction between cultures, which exacerbates all social, religious, cultural and linguistic aspects of interactions.

Foreign students face a complex phenomenon of trilingualism - the use of two foreign languages (for example, English, Ukrainian / Russian) for communication in while cognitive processes are accompanied and mediated by their native language (eg, Arabic, Syrian, etc.). The issue of linguistic and cultural identification and temporary mechanisms of its disorder remains difficult. These mechanisms being conscious as deficit-unmotivated but the functional quality of interaction causes numerous ambivalent conditions and disadaptation (V. Lunyov).

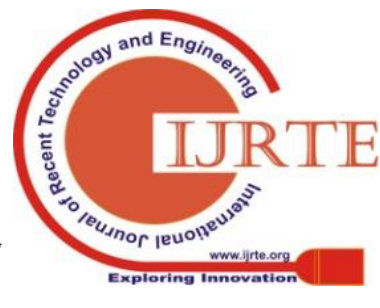


In this connection, studies need specific guidelines for trilingual adaptation in the context of the development of receptive language competences for foreign English speaking students. The issue of determining the interdependence of genetic-psychological peculiarities of neurotization (psycho-somatization) of the student's personality with the success of the acquisition of a professional language and training in the conditions of trilingualism is also relevant. In this context, it is discourse itself as a phenomenon of the linguistic environment and "linguistic personality" (J. Lakan, N. Chepeleva, S. Uvarova) acts as a condition for neurotization.

Also, the issue of the acquisition of a professional medical language in these circumstances remains unresolved, as well as the issue of determining the neurotization of foreign students taking into account the resourcefulness of their personalities, which in our opinion is conditioned by the constructiveness, deficiency and destructiveness of the I-functions ( G.Ammon). The practical point is also the question of the selection of methods of psychological influence in the educational process and psycho-correction practice, considering the principles of three linguistic learning spaces, linguistic and professional identification, disorders of adaptation and neurotization of personality.

Among the disciplines, studying on the first courses, which, in fact, occurs under conditions of trilingualism, medical microbiology with courses of virology and immunology is of great importance. The active use of theoretical statements of science for the construction of practical activity as a doctor is impossible without the presence of generalized methods of assimilation of scientific concepts that can be transposed to a new meaning. At the same time, the experience of teaching microbiological disciplines, suggests that in the program of training microbiology the question of generalized methods is not given due attention, psychological peculiarities of educational actions are not taken into account when assimilating the concepts of microbiology, not taking into account the trilingual situation of educational interaction.

Need to specify the general theoretical statements of the experimental genetic approach in the teaching English-speaking students under condition of trilingualism, the detection of the depth-psychological determinants of deficient, constructive and destructive I-functions, as well as the practical necessity of developing and introducing more effective forms of organization of educational activities in university practice in order to prevent factors of neurotization of students training in English in the conditions of trilingualism led to the choice of the topic of our research/

\section{METHODS}

In order to solve the set research tasks and to ensure the objectivity of the research, several general scientific and special methods have been used. 1. Methods of information gathering: theoretical methods - theoretical analysis of professional sources, system analysis and interpretation of the obtained data, classification, modeling, studying and generalization of experience; empirical methods - methods of observation, modeling, analysis of results of activity, psychodiagnostic techniques: Adaptation of a person to a new socio-cultural environment (L. Yankovskii); Symptomatic questionnaire (Simptom Check List-90-Revised) for assessing patterns of somatization of a personality;
Biographical questionnaire (BIV) for the diagnosis of behavioral disorders; Clinical questionnaire of Yakhin-Mendelevich for the detection and evaluation of neurotic conditions; I structural test of Ammon to determine the current state of the I-functions. 2. Methods of data processing: a) qualitative - methods of analysis, synthesis, comparison; b) quantitative - factor analysis, correlation analysis, mathematical modeling using STATISTICA (SPSS-22). 3. Interpretative methods: structural-genetic, phenomenological.

Experimental facilities of research: The research was conducted on the facilities of the O.O. Bogomolets National Medical University, the Odessa National University named after I.I. Mechnikov, Private higher educational institution

"Kyiv Medical University", Odessa National Medical University.

\section{RESULTS AND DISCUSSION}

It has been noted that vocational education is focused on constructs of the native language (based on the works of M.I. Zhynkin). The creation of the second foreign language (FL2) system in the consciousness of an individual has its own difficulties (A. Anisimova, N. Baryshnikov, R. Barsuk, I. Dubko, A. Schepylov, L. Sazhko, F. Usmanov, B. Hofaisen and others), trilingualism, in this sense, acts as a condition for the formation of receptive language competences of the second foreign language. Receptive linguistic competence appropriately should be defined as understanding and comprehension of the linguistic information in the $\mathrm{read} /$ listened texts, leading to a mutual communicational understanding between the addressant and the addressee (subjects of the educational process at higher educational institutions of the Ministry of Health of Ukraine).

Theoretical model of personality neurotization under conditions of trilingualism and assimilation of professional concepts (on the example of microbiology training) has been conceptualized - Fig. 1

The analysis of numerous studies of psychological peculiarities and the necessity of forming a system of educational actions, that are basis of discovering general relation, which underlies the content of theoretical concepts of the given area of knowledge (in our case, medicine) has been carried out. Author suggests that dichotomy "microorganism-macroorganism" can be a genetic relation. That can help to form and appropriate the system of microbiological concepts related to the clinical picture of an infectious disease. Using the system of assimilation of microbiological concepts has been proved as empirical and methodical material.

Consequently, experimental genetic approach (S.D. Maksimenko) to the teaching microbiology seems to be rational. The logic of this method implies not just the fixation of the peculiarities of certain empirical forms of manifestation of the person's psyche during observation or constructive thought experiment (in our case, the training of the system of microbiological concepts), but their active modeling and reproduction under special conditions, (in our case- in the condition of trilingualism). 
The specific feature of this modeling and constructing is that model created by the researcher for the cognitive purpose corresponds to the actual internal structure of the mental process.

The study was conducted in three stages. The first stage (2015-2016y.) included an analysis of scientific literature on the subject, which allowed substantiating the purpose, the research tasks for the further development of the methodical apparatus, to specify the object and subject of the study.

The second stage of the study (2016-2017y.) covered the immediate conduction of an empirical study. The determining, differentiations, structuring the results obtained during the empirical research were carried out.

At the third stage of the study (2017-2018 y.) the processing and analysis of empirical data obtained during the psychodiagnostic study took place.

To achieve the goal, an experimental genetic method, which allowed to actively model, reproduce psychological new formation under special conditions, was used (V. Davydov). Students' educational activities were researched through the creation of the program and content of the course of microbiology. On its basis the experimental training (S.D. Maksimenko), aimed at solving students' educational tasks, which required the creation of material and ideal actions was conduct.

The structure of the phenomenon of students' neurotization has been presented. Three-factor structure of the neurotization phenomenon has been determined by using factor analysis (SPSS-22).

The content of the first factor, "Deficiency neurotization", is represented by the following personal qualities of the trilingual students: in fact, the deficiency of the I-functions (0.964), disadaptation (-0.860), conformality (0.777), nostalgia (0.640), alienation (0.630), unfavorable family situation $(-0.785)$, social tension $(0.792)$, somatization (0.672), obsession (0.873), vegetative disorders $(0.562)$

The content of the second factor, "Destructive neurotization", combines such phenomena as: the actual destructiveness of the I-functions $(0,911)$, the experiences of the great influence of the parents' family $(0,705)$, neuroticism $(0,784)$, high social activity $(0,952)$, somatic disorders $(0,713)$, depression 0,819$)$, hysterical type of response $(0,689)$, high interference of concepts $(0,851)$.

The content of the third factor, "Anxious-ambivalent disadaptation" includes indexes of interactivity $(0,834)$, depression $(0,956)$, weakness of I $(-0,672)$, hostility $(0,678)$, phobia $(0,755)$, paranoyality $(0,753)$, anxiety $(0,921)$, neurotic depression (0.657), asthenia (0.772), receptive language competencies $(0.801)$. In general, the content of the factor indicates significant signs of the personality disadaptation.

Thus, the three-factor model of students' neurotization can be explained by the prediction of deficiency, destructiveness and weakness of the I-functions. Significant influence on the course of disadaptation processes is caused by the factors of internal connection with the homeland, which manifest themselves in nostalgia and a sense of alienation. Somatization of anxiety manifestations through the system of vegetative, depressive disorders, with low indexes of adaptability and high indexes of conformism, becomes one of the determinants of increasing neurotic conflict.
Table 1Factor matrix of neurotization as a form of personality determination

\begin{tabular}{|c|c|c|c|}
\hline & $\begin{array}{c}\text { Deficiency } \\
\text { neurotization }\end{array}$ & $\begin{array}{l}\text { Destructive } \\
\text { neurotization }\end{array}$ & $\begin{array}{l}\text { Anxious- } \\
\text { ambivalent } \\
\text { disadaptation } \\
\end{array}$ \\
\hline $\begin{array}{l}\text { Constructivity } \\
\text { of I- functions }\end{array}$ & 0,344 & 0,133 & 0,434 \\
\hline $\begin{array}{l}\text { Destructiveness } \\
\text { of I-functions }\end{array}$ & 0,234 & 0,911 & 0,234 \\
\hline $\begin{array}{l}\text { Deficiency of } \\
\text { I-functions }\end{array}$ & 0,964 & 0,111 & 0,328 \\
\hline Adaptability & $-0,860$ & 0,419 & $-0,032$ \\
\hline Conformality & 0,777 & 0,324 & 0,049 \\
\hline Interactivity & $-0,058$ & $-0,110$ & 0,834 \\
\hline Depressability & $-0,011$ & $-0,002$ & 0,956 \\
\hline Nostalgia & 0,640 & $-0,219$ & 0,566 \\
\hline Alienation & 0,630 & $-0,017$ & 0,554 \\
\hline $\begin{array}{l}\text { Family } \\
\text { condition }\end{array}$ & $-0,785$ & $-0,287$ & 0,214 \\
\hline Strength of I & $-0,311$ & $-0,150$ & $-0,672$ \\
\hline Social tension & 0,729 & $-0,843$ & $-0,042$ \\
\hline $\begin{array}{l}\text { Parents' } \\
\text { influence }\end{array}$ & $-0,005$ & 0,705 & 0,117 \\
\hline Neuroticism & $-0,008$ & 0,784 & 0,013 \\
\hline Social activity & 0,066 & 0,952 & $-0,109$ \\
\hline $\begin{array}{l}\text { Somatic } \\
\text { disorders }\end{array}$ & 0,030 & 0,713 & 0,222 \\
\hline Extroversion & 0,730 & 0,065 & 0,044 \\
\hline Somatization & 0,672 & 0,712 & 0,040 \\
\hline Obsession & 0,873 & $-0,028$ & $-0,001$ \\
\hline Depression & $-0,467$ & 0,819 & $-0,044$ \\
\hline Hostility & 0,245 & 0,223 & 0,678 \\
\hline Phobia & 0,197 & 0,341 & 0,755 \\
\hline Paranoyality & 0,367 & 0,232 & 0,753 \\
\hline Anxiety & 0,256 & 0,245 & 0,921 \\
\hline $\begin{array}{l}\text { Neurotic } \\
\text { depression }\end{array}$ & 0,255 & 0,121 & 0,657 \\
\hline Asthenia & 0,129 & 0,145 & 0,772 \\
\hline $\begin{array}{l}\text { Hysterical type } \\
\text { of reaction }\end{array}$ & 0,135 & 0,689 & 0,124 \\
\hline $\begin{array}{l}\text { Vegetative } \\
\text { disorders }\end{array}$ & 0,562 & 0,321 & 0,222 \\
\hline $\begin{array}{l}\text { Interference of } \\
\text { concepts (using } \\
\text { microbiology } \\
\text { material) }\end{array}$ & & 0,851 & \\
\hline $\begin{array}{l}\text { Receptive } \\
\text { language } \\
\text { competencies }\end{array}$ & & 0,801 & \\
\hline
\end{tabular}

An important result from the standpoint of the conceptual foundations of our study has turned out to be the high factor loading of index of the educational concepts interference (based on microbiology materials).

The concept of interference, which is understood as the negative influence of empirical generalizations against the background of trilingualism, has been specified.

The psychological features of interference have been determined depending on the level of scientific generalizations: with increasing level of scientific generalizations and receptive language competences, interference is significantly decreasing, neurotic models are slowing down. 


\section{CONCLUSIONS}

The basic conceptual approaches to the analysis of the essence, structure and mechanisms of neurotization as a form of personality determination based on analysis of theoretical and methodological papers of native and foreign authors have been determined. Neurotization has clinical-psychopathological and clinical-dynamic features associated with the form and stage of phenomenology. Typological characteristics of neurotization are based on its origin (personal, situational, proper neurotic variants) and interaction with other neurotic symptoms (fusion, coexistence, substitution).

Neurotization as a form of self-determination of the personality is associated with the mechanism of development of anxiety. Dynamics of anxiety in neurotic conditions is determined by a sequential change in the specific weight, place and role of its personal, situational and proper neurotic variants at different clinical stages of the process (reaction state - development).

The three-factor structure of the phenomenon of neurotization has been proposed.

\section{REFERENCES:}

1. Kostiuk O.V. (2018). The actualization of threelingualism problem as neurotization factor in the occupational training of future physicians. Innovations in Science: The Challenges of Our Time [Edited my Dei M., Rudenko O., Tsekhmister Ya., Lunov V.]. Hamilton: Accent Graphics Communications \& Publishing. P. 193-201.

2. Davletbaeva, Diana N., Li Meiqi, Minjar-Belorucheva, Alla P. (2018). Linguistic Knowledge Of Russian And English Bilinguism In Educational Discourse. MODERN JOURNAL OF LANGUAGE TEACHING METHODS, 8 (10), 419-422

3. Maksymenko, S. (2018). General psychological theories of development, study and education. Fundamental and Applied Researches in Practice of Leading Scientific Schools, 27(3), 221-235. https://doi.org/https://doi.org/10.33531/farplss.2018.3.28

4. Kapsambelis, V. (2019). Psychoanalytic Approaches to Psychotic Disorders in a Public Mental Health System. BRITISH JOURNAL OF PSYCHOTHERAPY, 35 (4), 577-585. DOI: 10.1111/bjp.12482

5. Obstein, K..L (2019). Continuing medical education (CME)/MOC ACTIVITIES. GASTROENTEROLOGY, 157 (6), E15-E18

6. Shyrobokov, V. P., Poniatovskyi, V. A., Yavorovskyi, O. P., Jankowskyi, D. S., Dyment, G. S., Bobyr, V. V. (2018). Influence of gel bentonite on physiological indicators of the white laboratory mice MEDICAL PERSPECTIVES-MEDICNI PERSPEKTIVI, 23 (4), 4-11. 